\title{
Respuesta inmunitaria ante la infección por SARS-CoV-2
}

\author{
Mónica Escamilla-Tilch ${ }^{1}$, Mario A. Téllez-González', Marcia Campillo-Navarro', Juan A. Suárez-Cuenca² \\ y Paul Mondragón-Terán ${ }^{1 *}$ \\ ${ }^{1}$ Coordinación de Investigación; 2Servicio de Investigación Clínica. Centro Médico Nacional 20 de Noviembre, Instituto de Seguridad y Servicios \\ Sociales de los Trabajadores del Estado, Ciudad de México, México
}

\section{Resumen}

Los coronavirus normalmente tienen hospederos en diversas clases taxonómicas, sin embargo, algunos de ellos tienen la capacidad de ser zoonóticos, causando sintomatología leve, mientras que los virus SARS-CoV y MERS-CoV causan enfermedades más severas, como el síndrome respiratorio del Medio Oriente (MERS) y el síndrome respiratorio agudo severo (SARS) en humanos. El pasado 2019 se reportaron una serie de casos de neumonía sin aparente causa. Al aislarse y conocerse la secuencia del genoma viral de manera oportuna, se determinó que el agente patológico era un nuevo tipo de coronavirus (CoV) que ocasionaba SARS, al cual refirieron como 2019-nCoV o SARS-CoV-2. Al ser un patógeno reciente, en un inicio se desconocía la respuesta del sistema inmunitario, sin embargo, tras diversos análisis y la rápida generación de información científica se han comenzado a conocer los mecanismos involucrados. En esta revisión analizaremos diferentes mecanismos inmunopatológicos involucrados durante la infección por SARS-CoV-2.

Palabras clave: SARS-CoV-2. COVID-19. Inmunopatología. Respuesta inmunitaria innata. Respuesta inmunitaria adaptativa.

\section{Immunological response to SARS-CoV-2 infection}

\begin{abstract}
Coronaviruses normally have hosts in various taxonomic classes, however, some of them have the capacity to be zoonotic, causing mild symptoms, while SARS-CoV and MERS-CoV viruses caused more severe diseases such as respiratory syndrome, Middle East (MERS) and severe acute respiratory syndrome (SARS) in humans. By the end of 2019 year, a series of cases of pneumonia with no apparent cause were reported in Wuhan China, when the sequence of the viral genome was isolated and known in a timely manner, it was determined that the pathological agent was a new type of coronavirus (CoV) which caused SARS, initially referred as 2019-nCoV, and now widely known as SARS-CoV-2. Being a recent pathogen, the response of the immune system was unknown, however, today and due to the rapid generation of scientific information, the mechanisms involved have begun to be understood. In this review we will analyze different immunopathological mechanisms involved during SARS-CoV-2 infection.
\end{abstract}

Key words: SARS-CoV-2. COVID-19. Immunopathology. Innate immune response. Adaptive immune response.

\section{Introducción}

A partir del 11 de febrero del 2020, la Organización Mundial de la Salud (OMS) denominó a la enfermedad infecciosa generada por el coronavirus 2 del síndrome respiratorio agudo grave (SARS-CoV-2) como COVID-19 (coronavirus disease 2019), la cual se originó en la Ciudad de Wuhan, China, y se caracteriza por una neumonía con etiología desconocida. Para el 30 de enero del 2020, el director general de la OMS

\footnotetext{
Correspondencia:

Fecha de recepción: 20-12-2020

*Paul Mondragón-Terán

Fecha de aceptación: 22-03-2021

Disponible en internet: 04-06-2021

E-mail: p.mondragonteran@gmail.com DOI: 10.24875/REMQ.M21000003

Rev Esp Méd Quir. 2020;25:88-100

www.remq-issste.com

1665-7330 / C 2021 Revista de Especialidades Médico-Quirúrgicas. Publicado por Permanyer México SA de CV. Este es un artículo Open Access bajo la licencia CC BY-NC-ND (http://creativecommons.org/licenses/by-nc-nd/4.0/).
} 
declaró que el brote es una pandemia, al convertirse en una emergencia de salud pública de importancia internacional. Actualmente hay más de 113,695,296 casos confirmados ${ }^{1}$. En México, los primeros casos confirmados se informaron el 28 de febrero de 2020: un caso en la Ciudad de México y el otro en el Estado de Sinaloa; sin embargo, el 1 de marzo del 2021 la Secretaría de Prevención y Promoción de la Salud en su comunicado técnico informa que se han confirmado $2,086,938$ casos y 185,715 defunciones $^{2,3}$.

El periodo de incubación del SARS-CoV-2 se encuentra de los 4 a 15 días y los síntomas más comunes de la COVID-19 son fiebre, disnea, tos seca y cansancio. Algunos pacientes pueden presentar dolores, congestión nasal, rinorrea, dolor de garganta o diarrea. Estos síntomas suelen ser leves y aparecen de forma gradual; algunas personas infectadas no desarrollan ningún síntoma, pasando la infección de manera desapercibida. La mayoría de los pacientes (alrededor del $80 \%$ ) se recuperan de la enfermedad sin necesidad de realizar ningún tratamiento especial. Además, una de cada seis personas que contrae COVID-19 desarrolla la enfermedad grave y muestra dificultades para respirar. Las personas de edad avanzada y las que padecen afecciones médicas subyacentes, como hipertensión arterial, problemas cardiacos o diabetes, tienen más probabilidades de desarrollar una enfermedad grave con un desenlace fatal ( 2\%). Asimismo, el número básico de reproducción o tasa de infección (R0, el promedio de casos secundarios producidos a partir de un caso) calculado mediante modelización de datos preliminares disponibles, se ha estimado entre 2 y 3; en el brote de Wuhan el R0 fue de 2-2.54.

La enfermedad se propaga de persona a persona por el contacto de microgotas procedentes de la nariz o la boca de una persona infectada que fueron expulsadas al toser o exhalar. Estas microgotas caen sobre los objetos y superficies, de modo que otras personas pueden contraer COVID-19 al tocar estos objetos o superficies y luego tocar sus ojos, nariz o boca. El contagio también puede ocurrir por la inhalación de estas microgotas, que contienen partículas virales, esparcidas en el aire alrededor de un paciente con COVID-195,6.

La infección por SARS-CoV-2 se ha clasificado en diferentes etapas dependiendo del grado de severidad de la enfermedad. La etapa inicial o asintomática es cuando ocurre en el establecimiento temprano de la enfermedad, implicando un periodo de incubación asociado con síntomas leves. Durante este periodo, el SARS-CoV-2 se multiplica utilizando el receptor de la enzima convertidora de angiotensina 2 (ECA2) como entrada a las células. En la segunda etapa, o periodo sintomático no severo, se establece la enfermedad pulmonar, el aumento de la multiplicación viral y la inflamación localizada en el pulmón. Finalmente, una minoría de pacientes con COVID-19 pasarán a la tercera y más grave etapa de la enfermedad, que se manifiesta como un síndrome de hiperinflamación sistémica extrapulmonar; en esta etapa, los marcadores proinflamatorios están elevados incentivando la hiperactivación de la respuesta inmunitaria que conduce hasta a una «tormenta de citocinas»"-9 (Fig. $1 \mathrm{~A}$ y C).

\section{Coronavirus 2 del síndrome respiratorio agudo grave}

Existen cuatro clases de coronavirus (CoV) que se designan como alfa, beta, gamma y delta; la clase de coronavirus beta incluye al virus del síndrome respiratorio agudo grave (SARS), el virus del síndrome respiratorio de Oriente Medio (MERS-CoV) y el SARSCoV-2, que genera COVID-19. Estos virus presentan similitudes debido a que afectan el sistema respiratorio inferior y generan neumonía, sin embargo, el SARSCoV-2 tiene una mayor tasa de transmisión/contagio y puede afectar al sistema gastrointestinal, corazón, hígado y sistema nervioso central llevando a la falla a múltiple de órganos ${ }^{10,11}$.

Los CoV pertenecen a la familia Coronaviridae del género Coronavirus, los cuales son virus envueltos con ácido ribonucleico (ARN) esférico y de tamaño aproximado de 120 a 160 nanómetros (nm). También poseen un genoma no segmentado de ARN monocatenario de polaridad positiva (27 a $32 \mathrm{~kb}$ ), poliadenilados en el extremo 3' y con nucleocápside helicoidal (9 a $11 \mathrm{~nm}$ de diámetro). En la parte externa de la envoltura del virus tiene proyecciones ampliamente distribuidas en forma de pétalos (20 nm de longitud), semejando una "corona solar». Las proteínas estructurales del virus consisten en la proteína de nucleocápside $(\mathrm{N})$ fosforilada de 50 a 60 kilodalton (kDa), la glucoproteína de membrana $(M)$ de 20 a $35 \mathrm{kDa}$, la cual ejerce como proteína de matriz en la doble capa de lípidos de la envoltura que interacciona con la nucleocápside, y la glucoproteína de espiga ( $\mathrm{S}$, de 180 a $220 \mathrm{kDa}$ ), que conforma las espículas de la "corona solar». Otros virus, como el $\mathrm{CoV}$ humano OC43 (HCoV-OC43), 


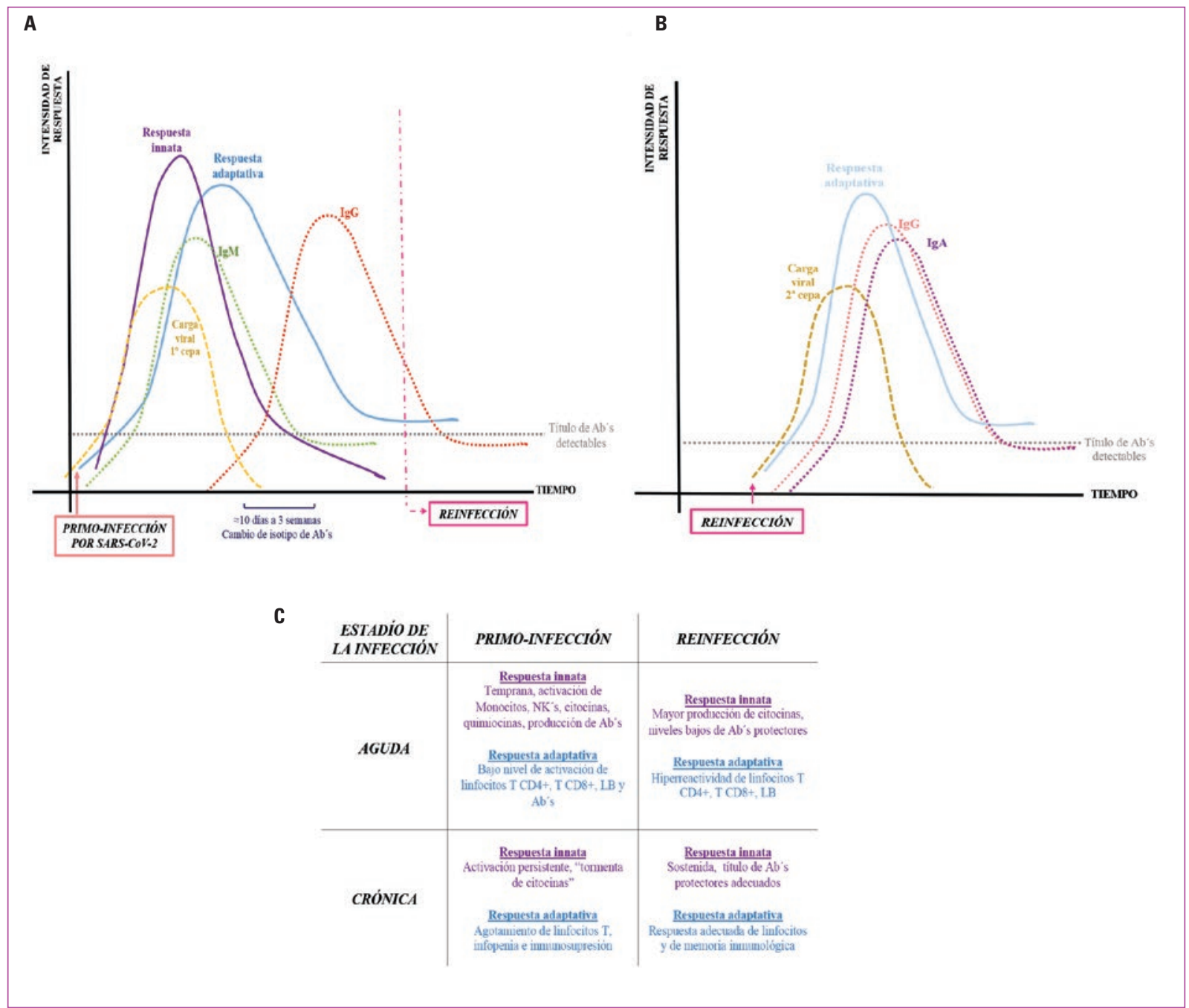

Figura 1. Respuesta inmunitaria durante la infección por SARS-CoV-2. A: en el gráfico se plasma la intensidad de la respuesta frente al tiempo durante la infección; la respuesta inmunitaria innata (morado) inicia inmediatamente al detectarse el inicio de la infección viral (amarilla) y se genera la producción de lgM (verde). Entre el día 10 a 3 semanas de infección inicia la respuesta adaptativa (azul), alcanzando su pico máximo, teniendo como efecto de la función temprana de ambas respuestas en sinergia, contribuyendo a la supresión viral y viéndose reflejada mediante el decaimiento de la carga viral y el cambio de isotipo a IgG (rojo). Cuando el título máximo de Ac protectores IgG (la línea gris punteada es el espectro de anticuerpos detectables por los métodos convencionales). B: intensidad de la reacción frente al tiempo durante la reinfección, dada por una segunda cepa o variante de SARS-CoV-2, activando la rápidamente la respuesta adaptativa con mayor intensidad, generando $\mathrm{Ac} \lg \mathrm{G}$ e $\lg \mathrm{A}$, en algunos casos (la línea gris punteada es el espectro de anticuerpos detectables por los métodos convencionales). C: en el cuadro se describe la activación de las células y mediadores celulares del sistema inmunitario implicados en la respuesta al SARS CoV-2 en la primoinfección y la reinfección, tanto en un estadio agudo como crónico de la enfermedad. SARS-CoV-2: coronavirus 2 del síndrome respiratorio agudo grave; Ig: inmunoglobulina; Ac: anticuerpos.

conservan una glucoproteína con actividad de acetilesterasa y causan hemaglutinación ( $\mathrm{HE}, 65 \mathrm{kDa})^{6}$.

Las proteínas estructurales que codifica el SARSCoV-2 son la proteína $S$ compuesta de dos subunidades S1 y S2, proteína E de envoltura, proteína M de membrana y la proteína $\mathrm{N}$ de nucleocápside; donde la más importante para el ingreso en las células del huésped es la proteína $\mathrm{S}$. La subunidad $\mathrm{S} 1$ se une a la ECA2 y la subunidad S2 es activada por la proteasa transmembranal de serina 2 asociada a la superficie del huésped (TMPRSS2) ${ }^{12-14}$. La ECA2 se expresa en diferentes órganos, como pulmón, corazón, riñones 
y tracto gastrointestinal; tiene actividad enzimática a través de sus dominios $\mathrm{N}$-terminal y $\mathrm{C}$-terminal, lo que le permite ejercer una actividad de carboxipeptidasa, dipeptidil-peptidasa, endopeptidasa, exopeptidasa y metalocarboxipeptidasa, así como la unión a iones de zinc y proteínas. Este receptor también contribuye en la maduración de angiotensina y en la regulación de diversos procesos como el transporte de aminoácidos, la contracción del músculo cardiaco, formación de especies reactivas de oxígeno (ROS), proliferación celular, producción de citocinas, la regulación de respuesta inflamatoria neuronal (neuroinmunomodulación), transporte de triptófano y otros neuropéptidos; cada una de las funciones son específicas de tejido/ órgano ${ }^{15}$.

\section{Inmunopatogenia de la infección por SARS-CoV-2}

La COVID-19 es una enfermedad multifactorial en la que se ha determinado que entre los factores de riesgo se encuentran: a) los determinantes sociales de la salud (SDH, social determinants of health), por ejemplo, nivel socioeconómico, acceso a la atención médica, entorno físico, redes de apoyo social y educación; b) el riesgo conocido de sus complicaciones debido a enfermedades preexistentes, y c) factores genéticos, entre otros. Los SDH y el estrés crónico ciertamente alteran las respuestas biológicas de una manera que aumenta el riesgo de enfermedad crónica ${ }^{16,17}$.

Sin embargo, algunos de los grandes cuestionamientos durante la pandemia por COVID-19 son: si la inmunidad adquirida en los pacientes es suficiente para generar una inmunidad; si en algún momento podría existir una reinfección viral, como sucede en otras infecciones por diversos virus; y si habrá alguna influencia sobre la respuesta inmunitaria durante la infección por SARS-CoV-2 dependiente del sexo.

Todos y cada uno de estos cuestionamientos nos llevan a analizar cada una de estas vertientes para tratar de dilucidar el rol que juegan durante la infección por SARS-CoV-2.

\section{Inmunidad innata: primera defensa antiviral al SARS-COV-2}

La inmunidad innata es la primera línea de defensa de un individuo, capaz de detectar y responder rápidamente frente a diversas infecciones, como las virales. El sistema inmunitario innato de pulmón está conformado por mediadores solubles (citocinas y quimiocinas), células fagocíticas como macrófagos, células dendríticas, mastocitos, monocitos y neutrófilos, así como por células epiteliales que recubren las vías respiratorias para formar una barrera contra el ambiente exterior ${ }^{18}$ (Fig. 2).

Actualmente, existe muy poco conocimiento de la respuesta inmunitaria innata a la infección por SARSCoV-2, por ello se han relacionado los mecanismos de respuesta inmunitaria ante otras cepas de coronavirus para entender mejor la COVID-19. EI SARS-CoV-2 ingresa a vías respiratorias del huésped e infecta las células de la mucosa que expresan los receptores ECA2 y TMPRSS2, replicándose inicialmente de manera intracelular en neumocitos y células epiteliales pulmonares del huésped ${ }^{12}$. La infección viral puede ser detectada por diversos receptores intracelulares conocidos como receptores de patrón de reconocimiento (PRR), que reconocen ARN viral como los del gen I inducible por ácido retinoico (RIG-I), la proteína 5 asociada a diferenciación de melanoma (MDA5), receptores tipo toll (TLR3, TLR7, TLR8, TLR9) y receptores tipo NOD con dominio de pirina (NLRP3, inflamasoma), entre otros receptores de respuesta antiviral ${ }^{19}$.

La detección de la proteína $S$ viral, los patrones moleculares asociados a patógenos (PAMP) generados durante la replicación viral y el ARN viral por diversas células de la inmunidad innata desencadenan varias vías de señalización que activan factores de transcripción como el factor nuclear kB (NF-kB) y la proteína activadora 1 (AP-1), los cuales inducen la liberación de una gran cantidad de mediadores proinflamatorios, como interleucina (IL) 6, IL-1 $\beta$, IL-2, IL-8, IL-17, factor estimulante de colonias de granulocitos (G-CSF), factor estimulante de colonias de granulocitos y monocitos (GM-CSF), proteína 10 inducible por interferón gamma (IP-10), proteína quimioatrayente de monocitos 1 (MCP-1), citocina CCL3 y factor de necrosis tumoral alfa (TNF- $\alpha$ ), que contribuyen a la inflamación patológica al prolongar el reclutamiento de células de la inmunidad innata, provocando lesiones pulmonares agudas y el síndrome de dificultad respiratoria aguda (SDRA) encontrado en casos graves de COVID-19. La producción exacerbada de citocinas y quimiocinas inflamatorias se denomina «tormenta de citocinas", donde la respuesta inmunitaria del huésped se encuentra reaccionando descontroladamente ante la infección viral ${ }^{20}$. 


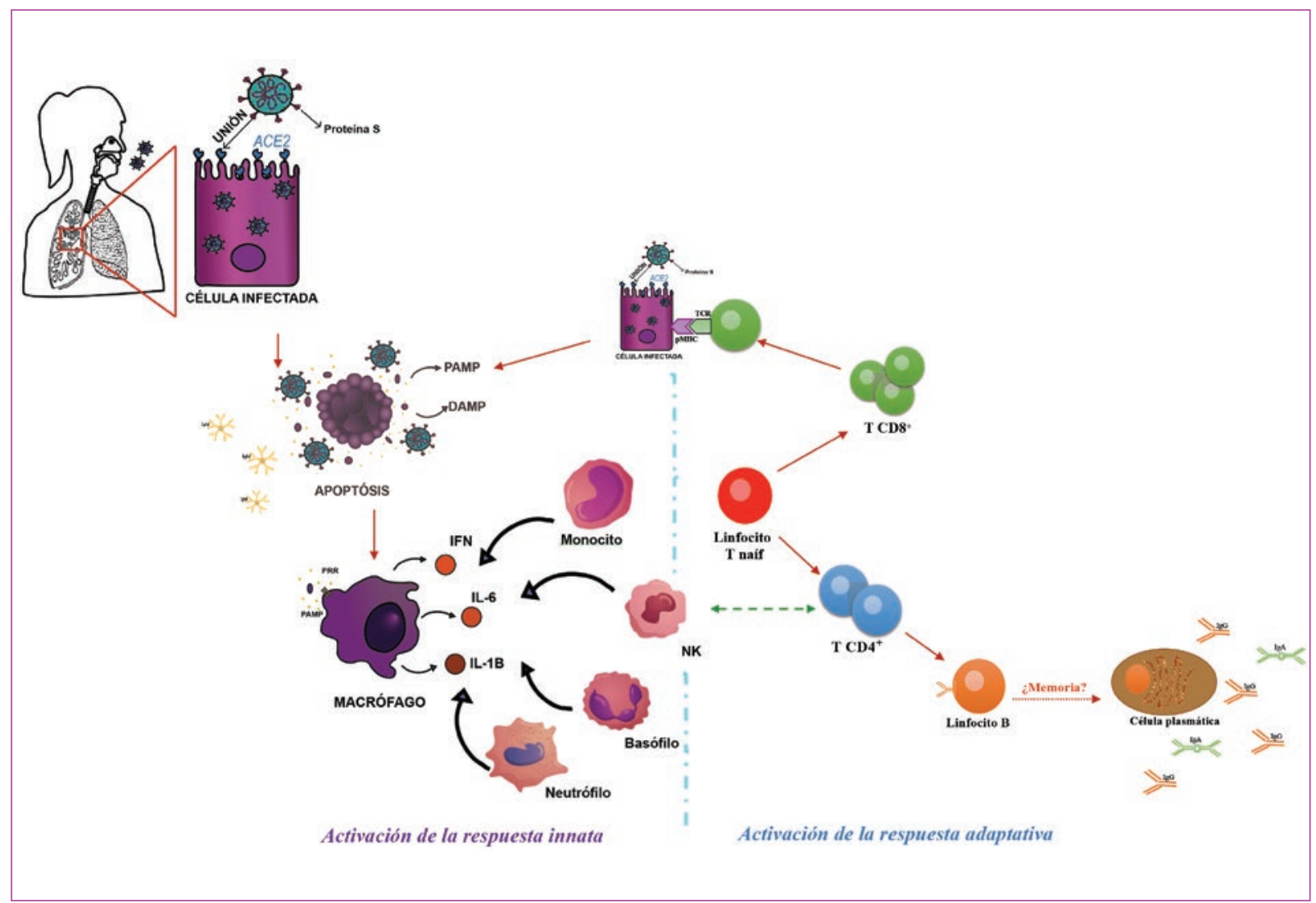

Figura 2. Esquema representativo de la activación del sistema inmunitario ante la infección por SARS-CoV-2. La enfermedad se propaga de persona a persona por el contacto con microgotas procedentes de la nariz o la boca de una persona infectada y que fueron expulsadas al toser 0 exhalar y que contienen partículas virales, esparcidas en el aire alrededor de un paciente con COVID-19. El SARS-CoV-2 se multiplica utilizando los receptores de ECA2 y TMPRSS2 como mecanismo de entrada a las células. En este punto la respuesta inmunitaria innata monta la primera barrera de defensa, al ser detectada por diversos receptores intracelulares PRR, que se encuentran en diversas células de la inmunidad innata (macrófagos, células dendríticas, mastocitos, monocitos y neutrófilos) y desencadenan varias vías de señalización que activan factores de transcripción como el NF-kB y la AP-1, los cuales inducen la liberación de una gran cantidad de mediadores proinflamatorios, como IL-6, IL-1 $\beta$, IL-2, IL-8, IL-17, G-CSF, GM-CSF, IP-10, MCP-1, citocina CCL3 y TNF- $\alpha$, que contribuyen a la inflamación patológica al prolongar el reclutamiento de células de la inmunidad innata. Posteriormente, se activa la respuesta inmunitaria adaptativa, en la cual participan los linfocitos T CD8+ con actividad citotóxica específica sobre las células infectadas y la producción de anticuerpos con la capacidad de neutralizar o bloquear la interacción del SARS-CoV-2 (proteína S) con sus receptores celulares ECA2 y TMPRSS2. Tanto para la activación adecuada de los linfocitos T CD8 ${ }^{+}$ citotóxicos, como para lograr una respuesta de anticuerpos madura y de alta afinidad (cambio de isotipo de $\operatorname{lgM}$ a IgG), se requiere de la participación de los linfocitos T CD4+ (Th1 y Th2) y la producción específica de citocinas. Además, las células NK son fundamentales debido a que actúan como link entre estas dos respuestas, ya que no solo tienen la capacidad de eliminar durante la respuesta innata a las células infectadas, sino que puede regular la respuesta de los linfocitos T por su grado activación. Sin embargo, al generarse una respuesta hiperactivada tanto de células como la producción exacerbada de citocinas y quimiocinas inflamatorias, puede desencadenarse lo que conocemos como "tormenta de citocinas", donde la respuesta inmunitaria del huésped reacciona descontroladamente ante la infección viral. SARS-CoV-2: coronavirus 2 del síndrome respiratorio agudo grave; COVID-19: enfermedad por coronavirus 2019; ECA2: enzima convertidora de angiotensina 2; TMPRSS2: proteasa transmembranal de serina 2 asociada a la superficie del huésped; PRR: receptores de patrón de reconocimiento; NF-kB: factor nuclear kB; AP-1: proteína activadora-1; IL: interleucina; G-CSF: factor estimulante de colonias de granulocitos; GM-CSF: factor estimulante de colonias de granulocitos y monocitos; IP-10: proteína 10 inducible por interferón gamma; MCP-1: proteína quimioatrayente de monocitos 1; TNF- $\alpha$ : factor de necrosis tumoral alfa; Th: T helper; NK: asesinas naturales; PAMP: patrones moleculares asociados a patógenos; DAMP: patrones moleculares asociados a daño/peligro. 
Los pacientes sintomáticos con COVID-19 muestran una expansión de monocitos inflamatorios (MI) en sangre periférica, mientras que los pacientes con la enfermedad severa presentan esta expansión de Ml en tejido pulmonar, en conjunto con el aumento considerable de neutrófilos y una diminución marcada de la cantidad de monocitos, eosinófilos, basófilos y células asesinas naturales (NK) en circulación sanguínea ${ }^{21-23}$. A pesar de la importancia de las células NK para la eliminación viral por la falta de expresión de ECA2, estas células se encuentran disfuncionales durante la infección por SARS-CoV-2, presentando una reducción en la expresión de CD107a, Ksp37, granzima B y granulisina, afectando la función citotóxica, producción de quimiocinas, TNF- $\alpha$ e interferones $(\mathrm{IFN})^{24}$. Una producción adecuada de IFN-I es esencial para el control y eliminación viral, pero desafortunadamente los pacientes con COVID-19 severa generalmente presentan niveles séricos bajos de IFN ${ }^{25}$. Por otro lado, en fluido de lavado bronco alveolar (BALF) de pacientes con COVID-19 se ha encontrado una gran cantidad de células de la inmunidad innata activadas, como células dendríticas, mastocitos, macrófagos derivados de monocitos y abundantes neutrófilos $^{26}$. El análisis de secuenciación del ARN de una sola célula de BALF de pacientes con COVID-19 grave mostró una acumulación de macrófagos inflamatorios clásicos $\mathrm{M} 1$ y macrófagos $\mathrm{M} 2^{21}$. El hallazgo de macrófagos M2 ha provocado preocupación, debido a que esta subpoblación se encuentra relacionada con la reparación de tejidos, formación de fibrosis y supresión de respuesta celular antiviral, que podrían alterar la resolución de la infección con secuelas fibróticas pulmonares ${ }^{26}$. Todos estos estudios muestran la posibilidad del transporte de células de inmunidad innata de circulación a tejido pulmonar, donde estas células responden descontroladamente, contribuyendo en la patogénesis de la tormenta de citocinas y un estado inflamatorio local que provoca daño pulmonar.

Por otro lado, se ha propuesto que la activación de las moléculas del complemento durante la infección por SARS-CoV-2 es de gran relevancia, ya que contribuye a la severidad de la patología; estos eventos comienzan al unirse el SARS-CoV-2 a la ECA2 en la superficie de las células endoteliales, iniciando la activación de la vía de las lectinas y posteriormente la vía clásica, lo que genera la formación de C3b, que incide en la vía alterna para la generación de C5 convertasa, esta escinde a la proteína C5, generando C5a y C5b-9. Los productos finales que se generan del complemento promueven la inflamación vascular mediante múltiples procesos, entre ellos la acción de la anafilatoxina $\mathrm{C5a}$, que recluta neutrófilos y monocitos/macrófagos. La C5b-9 y C5a inducen la liberación de IL-8 y MCP-1 por las células endoteliales y la expresión de moléculas de adhesión (molécula de adhesión intercelular 1, E-selectina, molécula de adhesión celular vascular 1), que favorecen la diapédesis (reclutamiento, adhesión y migración transendotelial) de neutrófilos y macrófagos. Posteriormente, los leucocitos infiltrantes liberan proteasas, citocinas proinflamatorias y ROS que contribuyen a la inflamación, la alteración de la matriz subendotelial y la remodelación, causando lesiones similares a la vasculitis. La C5a y el complejo de ataque de membrana (MAC, membrane attack complex) también inducen la exocitosis de los multímeros de P-selectina y factor de von Willebrand (VWF) de las células endoteliales que promueven la adhesión de plaquetas, y el desprendimiento de trombomodulina (TM) de la superficie celular endotelial, lo que desencadena la cascada de coagulación. Finalmente, las moléculas de C5b a C9 del MAC activan directamente las plaquetas, causando agregación plaquetaria y liberación de micropartículas procoagulantes (PMP). La sumatoria de todos estos eventos resultan en la lesión vascular y disfunción, con formación extensa de coágulos sanguíneos ${ }^{27-29}$.

Sin embargo, se han realizado muy pocos estudios respecto a la participación de las moléculas del complemento durante la infección por SARS-CoV-2. Magro, et al. realizaron un estudio en el cual examinaron biopsias de piel y pulmones de cinco pacientes con COVID-19 grave caracterizada por insuficiencia respiratoria $(n=5)$ y erupción cutánea purpúrica $(n=3)$. La neumonitis por COVID-19 fue predominantemente una lesión capilar septal inflamatoria pauciinflamatoria con deposición de fibrina mural, capilar septal significativa y permeación de los septos interalveolares por neutrófilos. Estos hallazgos pulmonares se acompañaron de depósitos de componentes del complemento C5b-9 que forman el MAC, C4d y serina proteasa asociada a las manosas unidoras de lectina 2 (MBL2-MASP, mannose-binding lectin-associated serine proteases), en la microvasculatura, consistente con la activación sistémica sostenida de las vías del complemento. Las lesiones cutáneas purpúricas mostraron de manera similar una vasculopatía trombogénica pauciinflamatoria, 
con depósito de C5b-9 y C4d tanto en la piel gravemente afectada como en la de aspecto normal. Además, hubo colocalización de proteínas spike (S) de COVID-19 con C4d y C5b-9 en los tabiques interalveolares. Por lo que concluyen que los pacientes con COVID-19 pueden presentar un tipo de síndrome de lesión microvascular mediado por la activación de las vías del complemento y un estado procoagulante asociado ${ }^{30}$.

\section{Inmunidad adaptativa: ¿aliada o enemiga?}

La transición entre la respuesta inmunitaria innata y la adaptativa es un punto clave para la resolución de la infección, de tal forma que la respuesta adaptativa o adquirida se caracteriza por tener especificidad, especialización, diversidad, autorregulación y memoria. Dos de los participantes fundamentales en la respuesta adquirida son los linfocitos $\mathrm{T} \mathrm{CD}^{+}$con actividad citotóxica específica sobre las células infectadas y la producción de anticuerpos con la capacidad de neutralizar o bloquear la interacción del SARS-CoV-2 (proteína S) con sus receptores celulares ECA2 y TMPRSS2. Tanto para la activación adecuada de los linfocitos T CD8 ${ }^{+}$, como para lograr una respuesta de anticuerpos madura y de alta afinidad (cambio de isotipo de inmunoglobulina [lg] M a IgG), se requiere de la participación de los linfocitos $T$ $\mathrm{CD}^{+}$(Th1 y Th2) y la producción específica de citocinas. Además, como se ha mencionado, las células NK son fundamentales debido a que actúan como link entre estas dos respuestas jugando el rol de "Cerbero custodiando las puertas del Averno", ya que no solo tienen la capacidad de eliminar durante la respuesta innata a las células infectadas, sino que pueden regular la respuesta de los linfocitos $T$ por su grado activación ${ }^{31-33}$ (Fig. 2).

Se han analizado células NK tanto en muestras de sangre periféricas como de lavado broncoalveolar de pacientes con COVID-19, identificando distintos inmunofenotipos de NK relacionados con la gravedad de la enfermedad. Los inmunofenotipos característicos encontrados fueron de alta expresión de perforina, NKG2C y Ksp37, lo que refleja una mayor presencia de células NK de respuesta adaptativa en la circulación de pacientes con enfermedad grave; asimismo, se asoció la activación y expansión de las células NK CD56 bright adaptativas con los estados de la enfermedad de COVID-19, sobre todo con una severa hiperinflamación ${ }^{34}$.
Se sabe que durante el desarrollo de la patología existe un impacto en las poblaciones de linfocitos $T$, $B$ y NK, propiciando linfopenia asociada a casos severos de la enfermedad ${ }^{35-37}$, asimismo el microambiente dictado por las citocinas influye tanto en la hiperactivación como en la linfopenia; se ha observado que en aquellos pacientes con estadios graves, la linfopenia puede estar asociada a niveles elevados de IL-6, IL-10 o TNF- $\alpha$; mientras que durante la hiperactivación pudiese estar asociada al incremento de la expresión de moléculas proapotósicas, como FAS (conocida también como CD95), TRAIL o la caspasa $3^{36,38,39}$

Un estudio conducido por Huang, et al. concluye que los pacientes infectados con COVID-19 con altos niveles de IL-1B, IFN- $\gamma$, IP-10 y MCP-1 probablemente presentan una respuesta tipo Th1. Además, los pacientes que requirieron ingreso en la unidad de cuidados intensivos $(\mathrm{UCl})$ presentan niveles más altos de G-CSF, IP-10, MCP-1, MIP-1A y TNF- $\alpha$ que aquellos que no requirieron ingreso en la $\mathrm{UCl}$, lo que sugiere que la tormenta de citocinas podría estar asociada con la gravedad de la enfermedad, pero la infección por COVID-19 promovió una mayor secreción de citocinas tipo Th2, que pudiesen suprimir la inflamación ${ }^{9}$.

Por otro lado, en la infección moderada por COVID-19 hay una elevación progresiva en los niveles de anticuerpos (Ac) IgM e IgG, aunado a un incremento en el reclutamiento de células plasmáticas, las células T helper foliculares (células TFH) y de las células $T$ $\mathrm{CD} 4{ }^{+} \mathrm{CD} 38^{+} \mathrm{HLA}-\mathrm{DR}$ (fenotipo de células activadas), aunque en menor proporción; pero más importante, un incremento de las células $\mathrm{T} \mathrm{CD} 8^{+} \mathrm{CD} 38^{+} \mathrm{HLA}$-DR (fenotipo de células activadas) en sangre periférica antes de la recuperación sintomática. Por lo que se considera que una respuesta sostenida y adecuada de las células ASC, células TFH, los linfocitos CD4 ${ }^{+}$, pero sobre todo de los linfocitos T CD8 ${ }^{+}$, junto con el incremento de Ac IgG e lgM podrían ser marcadores de buen pronóstico, ya que podrían contribuir a la resolución ${ }^{40}$.

De igual modo, se ha observado que la magnitud y la prevalencia de la respuesta de linfocitos $\mathrm{T} \mathrm{CD} 4^{+}$se correlaciona con el nivel de expresión de proteínas de SARS-CoV-2, tanto las proteínas $\mathrm{S}, \mathrm{M}$ y $\mathrm{N}$ que son blancos principales, como ORF3 y nsp3; el incremento de la respuesta que se monta contra la proteína $\mathrm{M}$ (proteína pequeña transmembranal) es debido a la fuerte afinidad que tienen las células $\mathrm{T} \mathrm{CD4}^{+}$, lo que 
podría sugerir que tiene una alta expresión in vivo, o bien es una proteína altamente inmunogénica. Además, se ha considerado que la proteína $S$ es un antígeno inmunodominante con alta inmunogenicidad, sin embargo, a partir de un análisis de un megapool de epítopes del MHC (complejo mayor de histocompatibilidad) clase II para predicción de la respuesta, se determinó que $\sim 50 \%$ de la afinidad de los linfocitos $T$ $\mathrm{CD}^{+}$es dirigido a otras proteínas independientemente de $S^{41-43}$.

De manera alternativa, se sugiere que los linfocitos T CD8 ${ }^{+}$podrían estar en un estado hiperactivo, al tener altos niveles de marcadores de citotoxicidad, incrementando el número de células $\mathrm{T} \mathrm{CD}^{+}$activas con inmunofenotipo $\mathrm{CD}^{2} 8^{+} \mathrm{HLA}-\mathrm{DR}^{+}$o de células $\mathrm{T} \mathrm{CD} 8^{+}$ proliferativas con inmunofenotipo $\mathrm{Ki}^{+} 7^{+}$; estos inmunofenotipos se han determinado en sangre periférica de los pacientes durante la fase aguda de la infección o después de la vacunación, sin embargo, posiblemente no sea el único inmunofenotipo presente en los diversos estadios de la enfermedad ${ }^{36,40,41}$.

\section{Diferencias en la respuesta inmunitaria antiviral por influencia del sexo}

Actualmente sabemos que uno de los factores de susceptibilidad relevantes durante la infección y desarrollo por COVID-19 es el sexo (hombres vs. mujeres). Se han realizado diversos estudios en infecciones virales donde se muestra que las mujeres tienen una respuesta inmunitaria más fuerte durante las infecciones virales en comparación con los hombres debido a las respuestas inmunitarias humorales y celulares; como se ha mencionado la respuesta inmunitaria innata es la primera línea de defensa contra cualquier infección viral, al estar mediada principalmente por diferentes clases de PRR, como los TLR que detectan componentes virales, como el ARN monocatenario; además, los TLR regulan específicamente la producción de IFN-I y otras citocinas ${ }^{44,45}$.

El dimorfismo sexual se observa durante las respuestas antivirales mediadas por la vía TLR e IFN, las células inmunitarias en mujeres exhiben una expresión 10 veces mayor de TLR en comparación con los hombres, además el número y la actividad de las células inmunitarias innatas como los monocitos, los macrófagos y las células dendríticas son más altos en las mujeres que en los hombres. De esta manera, la respuesta inmunitaria adaptativa también representa una gran parte de las diferencias sexuales en respuesta a las infecciones virales. Dependiendo de la etapa de la infección, las mujeres exhiben mayor respuesta Th1 y Th2 en comparación con los hombres; además, se observa una regulación positiva de los genes antiinflamatorios y una mayor actividad de las células T CD8 ${ }^{+}$ citotóxicas y linfocitos $T$ reguladores en las mujeres, mientras que se han encontrado niveles más bajos de células $\mathrm{T} \mathrm{CD}^{+}, \mathrm{CD}^{+}$y $\mathrm{CD} 4^{+}: \mathrm{CD} 8^{+}$en hombres en comparación con mujeres ${ }^{45,46}$.

Aunado a lo anterior y posiblemente debido a diferencias inmunitarias basadas en el sexo, además del rol potencial de los estrógenos (17ß-estradiol, E2). El E2 se une a sus receptores alfa y beta (ER- $\alpha$ y ER- $\beta$ ) expresados en la superficie de distintas células de la respuesta inmunitaria, por ejemplo, el ER- $₫$ se expresado más en linfocitos $T$, incluye células hematopoyéticas, médula ósea, células del estroma del timo y timocitos; mientras que el ER- $\beta$ tiene una expresión celular más restringida y se expresa preferentemente en el timo y el bazo del feto humano de gestación media en linfocitos $B$, además los estrógenos estimulan la respuesta humoral incrementando los niveles de Ac y la activación de células plasmáticas (o célula secretora de anticuerpos, ASC) ${ }^{47}$.

Con respecto a la infección por SARS-CoV-2, en un estudio estratificado por sexo, los pacientes con COVID-19 muestran un número igual de casos entre hombres y mujeres. Estos desarrollan hipoxemia severa, presentan pequeños trombos fibrinosos en arteriolas pulmonares, además de una tumefacción endotelial en las autopsias de casos fatales de COVID-19, asimismo induce un proceso vascular en el pulmón, que incluye vasodilatación y disfunción endotelial; hubo una disminución en el número de linfocitos T $\mathrm{CD} 4^{+}$y $\mathrm{T} \mathrm{CD} 8^{+}$en pacientes con infección grave. Sin embargo, parece haber diferencias de sexo en la tasa de mortalidad y vulnerabilidad a la enfermedad, por lo que sugieren que el estradiol está conectado con el número de linfocitos T CD4 ${ }^{+}$, aumentando así las poblaciones de células $\mathrm{T}$ reguladoras (Treg), lo que afecta la respuesta inmunitaria durante la infección. Aunado a lo anterior, se sabe que el estradiol ejerce un efecto protector sobre la función endotelial, activando la generación de óxido nítrico por medio de la sintetasa de óxido nítrico endotelial. Por otro lado, el estrógeno atenúa la respuesta vasoconstrictora a varios estímulos e induce vasodilatación en la vasculatura pulmonar durante situaciones de estrés como la hipoxia, también ejerce una variedad 
de acciones rápidas, que se inician después de su acoplamiento con los receptores de membrana que, a su vez, pueden modular positivamente las respuestas vasculares en la enfermedad pulmonar y ayudar a mantener el flujo microvascular ${ }^{47,48}$.

Se ha observado que en la fase temprana de la respuesta inmunitaria antiviral de ratones, las producción de citocinas proinflamatorias fueron elevadas en ambos sexos, mientras que en ratones hembras, la producción abundante de citocinas indujo una mayor expresión de aromatasa y síntesis de estrógenos que en los machos; al cabo de 72 horas postinfección, los altos niveles de estrógenos y su interacción con sus receptores silenciaron la tormenta de citocinas causada y eliminaron los exudados acumulados de células inflamatorias, algo que no logró observarse en los ratones macho, puesto que sus niveles de estrógenos son menores ${ }^{49}$.

Otras moléculas, como estrógenos conjugados, han demostrado que pueden aumentar la expresión génica de ECA2/Ang1-7; este mecanismo podría aminorar el daño pulmonar, endotelial y la coagulopatía en pacientes graves con COVID-1924,50. Aunado a ello se ha demostrado que la diabetes tipo 2 inhibe a los estrógenos, lo cual se ha relacionado con una disrupción en la respuesta inmunitaria ante el virus de la influen$z^{51}$. Chen, et al. demostraron que los pacientes diabéticos e hipertensos muestran una disminución de la expresión de ECA2/Ang 1-7, además establecieron una correlación negativa entre las hormonas de estrógenos y andrógenos con la expresión de ECA2 y la mortalidad de los pacientes con COVID-1952.

\section{Reinfección por SARS-CoV-2}

A partir de los casos de reinfecciones que se han reportado, se considera que podrían estar influidos por diversos mecanismos como los descritos a continuación.

\section{Variación genética del virus (cepas virales)}

Se ha mencionado al respecto de la variabilidad en el genoma viral que podría llevar a generar una cepa más patogénica, ya que para marzo del 2020 ya se había realizado un estudio publicado en la revista Scientific Reports, en el cual se describe las firmas genómicas del virus de ARN, para lo cual se analizaron 2,492 secuencias genómicas completas de las cepas de SARS-CoV-2 ingresadas en la base de datos del Global Influenza Surveillance and Response System (GISAID, que es una iniciativa científica que brinda el acceso abierto a datos genómicos de influenza y coronavirus [https://www.gisaid.org/]). Sumado a lo anterior, evidencias sugirieron que la transmisión de la COVID-19 está asociada con las condiciones climáticas, es decir con condiciones secas y frías que parecen impulsar la propagación de las infecciones; así como la tasa de mortalidad por día de COVID-19, lo cual se asocia positivamente con el rango de temperatura diurna, pero negativamente con la humedad relativa; por lo que la integración de datos geográficos y climáticos con el análisis de mutaciones genéticas condujo a una comprensión más completa de los orígenes, la dispersión y la dinámica del SARS-CoV-2 en evolución. El análisis del genoma reveló 1,516 variaciones de nucleótidos en diferentes posiciones en todo el genoma; además, el análisis de deleción de nucleótidos encontró 12 sitios de deleción en todo el genoma distintos a parte de las deleciones ya reportadas en la secuencia codificante de las proteínas ORF8 (marco de lectura abierto), proteína $S$ y ORF7a, específicamente en la poliproteína ORF1ab ( $n=9)$, ORF10 ( $n=1)$ y 3'-UTR $(n=2)$. La evidencia de los análisis sistemáticos del perfil de proteínas y mutaciones a nivel de genes reveló una gran cantidad de sustituciones de aminoácidos $(n=744)$, lo que demuestra que las proteínas virales son heterogéneas. En particular, los residuos del dominio de unión al receptor, que muestra interacciones cruciales con la ECA2 y los anticuerpos neutralizantes, los cuales se conservan entre las cepas del virus, excepto por el reemplazo de lisina con arginina en la posición 378 del epítopo aislado de Shanghái, hCoV-19/Shanghái/ SH0007/2020 (EPI_ISL_416320). Además, los resultados de los datos epidemiológicos preliminares sobre infecciones por SARS-CoV-2 revelaron que la frecuencia de mutaciones de aminoácidos fue relativamente mayor en las secuencias de Europa (43.07\%), seguida de Asia (38.09\%) y Norteamérica (29.64\%), mientras que las tasas de letalidad se mantuvieron más altas en los países europeos templados, como Italia, España, Países Bajos, Francia, Inglaterra y Bélgica. Por lo tanto, en este análisis se proponía que el método de análisis del genoma podía ser una herramienta prometedora para monitorear y rastrear la situación pandémica en continua evolución, las variantes genéticas asociadas y sus implicaciones para el desarrollo de estrategias efectivas de control y profilaxis $^{10,53,54}$. 
Casos de reinfección por cepas virales distintas asociadas a la intensidad de la respuesta inmunitaria de la primoinfección

Un estudio de caso realizado en China en un paciente varón de 33 años con una segunda infección después de viajar a España demuestra que durante la segunda infección (reinfección) ocurrida 142 días después del primer episodio es asintomático, sin embargo, presenta una elevación en la proteína $C$ reactiva y anticuerpos IgG específicos para SARS-CoV-2, lo que sugiere que se trata de un episodio genuino de infección aguda. Para determinar si los genomas virales eran los mismos en ambos episodios, se realizó una secuenciación de genoma completo por la cual se determinó que pertenecen a diferentes linajes. El primer genoma del virus estaba estrechamente relacionado filogenéticamente con las cepas recolectadas en marzo/abril de 2020, mientras que el segundo genoma del virus tenía una relación más estrecha con cepas recolectadas en julio/agosto de 2020. Aunado a lo anterior, se describen otras diferencias en la proteína $S$ de aproximadamente 23 nucleótidos y 13 aminoácidos ubicadas en nueve proteínas diferentes (incluidas aquellas en las posiciones de los epítopos de las células B y T) entre los virus del primer y segundo episodio, lo cual podría conllevar que el virus sea menos susceptible a la detección por lo anticuerpos generados en la primera infección. Por lo que Kai-Wang, et al. consideran que las reinfecciones podrían deberse a infecciones de cepas de virus con secuencias genómicas diferentes entre la primera y la segunda infección ${ }^{55}$.

Así mismo, cuando analizaron los títulos de anticuerpos durante la reinfección encontraron $\lg G$ de alta avidez y títulos altos de anticuerpos neutralizantes, lo que sugiere que la primera inmunización del primer episodio ha permitido una respuesta de anticuerpos más robusta durante el segundo episodio. Sin embargo, a medida que el título de anticuerpos disminuye con el tiempo, una proporción creciente de pacientes que tuvieron COVID-19 se volverían susceptibles a la reinfección ${ }^{56}$.

Esto es especialmente importante, ya que un caso de reinfección reciente mostró que la reinfección puede ser más grave que la primera infección, este caso se reportó por Tillett, et al. El paciente era un hombre de 25 años del Estado de Nevada, sin trastornos inmunitarios conocidos, que tuvo una infección por SARS-CoV-2 confirmada por reacción en cadena de la polimerasa (PCR) en abril de 2020 (muestra A). Se recuperó en cuarentena, dando negativo por RT-PCR en dos momentos consecutivos a partir de entonces. Sin embargo, 48 días después de la prueba inicial, el paciente volvió a dar positivo mediante RT-PCR (muestra B). La secuenciación del genoma viral mostró que los especímenes $A$ y B pertenecían a la cepa viral $20 \mathrm{C}$ (predominantemente observada en el norte de Nevada), sin embargo, las secuencias del genoma de los aislados de la primera infección (muestra A) y la reinfección (muestra B) diferían significativamente, lo que reducía la posibilidad de que el virus fuera de la misma infección. La reinfección por SARS-CoV-2 resultó en una enfermedad más grave que la primera infección, requiriendo soporte de oxígeno y hospitalización, el paciente mostró anticuerpos positivos después de la reinfección, pero se desconoce si tenía anticuerpos preexistentes después de la primera infección ${ }^{57}$. De esta manera, consecutivamente se han ido reportando los casos de reinfecciones donde la cepa viral de SARS-CoV-2 y la respuesta inmunitaria contribuyen a un mejor o peor pronóstico y recuperación del paciente.

\section{Título de anticuerpos}

Está claro que la mayoría de las personas infectadas con SARS-CoV-2 muestran una respuesta de anticuerpos entre 10 y 14 días después de la infección. En algunos casos leves, la detección de anticuerpos requiere mucho tiempo después de los síntomas, y en un pequeño número de casos los anticuerpos no se detectan en absoluto. Se sabe que los anticuerpos contra otros coronavirus humanos disminuyen con el tiempo, y hay algunos informes de reinfección con coronavirus homólogos después de tan solo 80 días, por lo tanto, la reinfección de casos de SARS-CoV-2 previamente leves es una posibilidad realista que debe considerarse en los modelos de posteriores olas y la era pospandémica. Además, las personas con títulos bajos de anticuerpos después de una enfermedad leve deben ser objeto de seguimiento para detectar evidencia de reinfección y enfermedad recurrente mediante un monitoreo clínico regular y detección de virus de diagnóstico por RT-PCR. Si se detecta una reinfección, se deben establecer la carga viral en serie y las medidas del estado de los anticuerpos en el momento de la reinfección. Es posible y probable que los mecanismos de protección por medio de la respuesta inmunitaria (memoria y células T citotóxicas) alteren el curso de la COVID-19 en la 
reinfección, ya sea disminuyendo los síntomas en ausencia de anticuerpos protectores o mejorando la infección al evadir la respuesta inmunitaria humoral subneutralizando los títulos de anticuerpos ${ }^{58}$ (Fig. 1 B y C).

\section{Fondo genético}

En diversos estudios se ha comenzado a analizar cómo el fondo genético y las variantes en este pueden asociarse al desarrollo o desenlace durante la infección por SARS-CoV-2. Un estudio del consorcio GenOMICC, que incluye a 2,244 controles y pacientes COVID-19 en estado crítico, identifica tres nuevos locus ubicados en los cromosomas 12, 19 y 2, con efectos significativos en el estudio de genoma completo, además del locus de susceptibilidad en el cromosoma $3^{59}$.

Por otro lado, uno de los estudios más interesantes es el de Zerberg y Pääbo, del Instituto Max Planc, que publicaron sus hallazgos referentes a que aquellas variantes genéticas de protección frente al desarrollo de COVID-19 severa están relacionadas con un haplotipo heredado por los neandertales. Los neandertales y los denisovanos son grupos de homínidos arcaicos que se extinguieron hace unos 40,000 años y tienen un impacto biológico en la fisiología humana actual por medio de contribuciones genéticas a las poblaciones humanas modernas que ocurrieron durante las últimas decenas de miles de años de su existencia. Varias de estas contribuciones afectan a genes involucrados en el sistema inmunitario, en particular las variantes en locus que contienen genes involucrados en la inmunidad innata ${ }^{60}$.

Al identificar haplotipos de alelos neandertales que se segregan conjuntamente en los seres humanos que viven hoy en día, encontramos un segmento similar al neandertal de 90 kilobases (kb) (chr12: 113,345,168113,435,449; hg19) que se superpone a la región genómica que alberga polimorfismos de nucleótido simple (SNP, por sus siglas en inglés) asociados con COVID-19 grave. El alelo índice, es decir, el alelo neandertal con la mayor asociación con COVID-19 severa (rs4766664), ocurre en todas las poblaciones de Eurasia y América en frecuencias que a menudo alcanzan y superan el $30 \%{ }^{50,61}$.

El haplotipo neandertal que protege frente a la $\mathrm{CO}$ VID-19 severa se encuentra en una región del cromosoma 12 que contiene los tres genes OAS1, OAS2 y OAS3, los cuales codifican a enzimas de oligoadenilato sintetasas. Estas enzimas son inducidas por IFN y activadas por ARN bicatenario, producen poliadenilatos de cadena corta, que a su vez activan la ribonucleasa $L$, que degrada el ARN intracelular, y activan otros mecanismos antivirales en las células infectadas. El alelo más común en el SNP rs10774671 (T>A / T>G) afecta el sitio de splicing de la transcripción OAS1 que produce una isoforma de proteína ancestral (p46), de tal forma que se ha demostrado que la isoforma ancestral, conservada en los neandertales, tiene una mayor actividad enzimática. Fuera de África, el alelo ancestral solo está presente en individuos con el haplotipo neandertal, mientras que en África existe independientemente de este haplotipo, presumiblemente como una variante genética heredada de los ancestros comunes de los humanos modernos y neandertales que se perdió en la población humana moderna que abandonó África. Además, las versiones neandertales de los genes OAS se expresan de manera diferente en respuesta a diferentes infecciones virales tanto en términos de niveles de expresión como de formas de splicing alternativo. Por lo tanto, es muy posible que el locus de la OEA haya estado sujeto a distintas presiones selectivas de diferentes patógenos durante los cientos de miles de años que los neandertales y los antepasados de los humanos modernos vivieron en Eurasia occidental y África subsahariana, respectivamente $e^{60,61}$.

\section{Conclusión}

A lo largo de la historia de la humanidad diversas enfermedades han ido de la mano con el movimiento de las poblaciones, por lo que en el caso del SARSCoV-2 no es la excepción, de tal forma que la presión evolutiva de dichos organismos desde el inicio ha generado la evolución de la respuesta inmunitaria, aunado a esto, el estilo de vida impacta en diversas formas en el desarrollo de nuevas patologías.

La evidencia con que contamos actualmente con respecto a la infección por SARS-CoV-2 nos indica la relevancia que tiene no solo la pronta respuesta del sistema inmunitario, sino la capacidad e intensidad adecuada para montar una respuesta proporcionada, sin embargo, hay diversos factores que influyen durante el desarrollo de la infección, como comorbilidades previas, edad, sexo, fondo genético (etnicidad) y factores de determinantes sociales, entre otros.

La regulación de la respuesta inmunitaria está dada tanto por la respuesta inmunitaria innata (citocinas, quimiocinas, macrófagos, células dendríticas, mastocitos, 
monocitos y neutrófilos) como la respuesta adaptativa (NK, linfocitos T y B), la autorregulación e intensidad de ambas es necesaria para poder eliminar la infección, esta deberá ser lo suficientemente intensa para generar memoria, pero no daño.

Aún seguimos dilucidando el mecanismo inmunopatológico, los mecanismos de evasión al sistema inmunitario por el SARS-CoV-2 y aquellas moléculas involucradas que puedan ser usadas como blancos terapéuticos e incluso los elementos necesarios para mejorar las vacunas ya desarrolladas. Sin embargo, por lo que conocemos hasta hoy, solo estamos en el preámbulo de la historia de la pandemia de COVID-19.

\section{Financiamiento}

La presente investigación no ha recibido ninguna beca específica de agencias de los sectores públicos, comercial o sin ánimo de lucro.

\section{Conflicto de intereses}

Los autores declaran no tener conflictos de interés alguno.

\section{Responsabilidades éticas}

Protección de personas y animales. Los autores declaran que para esta investigación no se han realizado experimentos en seres humanos ni en animales.

Confidencialidad de los datos. Los autores declaran que han seguido los protocolos de su centro de trabajo sobre la publicación de datos de pacientes.

Derecho a la privacidad y consentimiento informado. Los autores declaran que en este artículo no aparecen datos de pacientes.

\section{Bibliografía}

1. World Health Organization. Report of the WHO-China Joint Mission on Coronavirus Disease 2019 (COVID-19) [Internet]. World Health Organization 16-24 de febrero de 2020. Disponible en: https://www.who.int/ docs/default-source/coronaviruse/who-china-joint-mission-on-covid19-final-report.pdf

2. Secretaría de Salud, Secretaría de Prevención y Promoción de la Salud. Comunicado Técnico Diario [Internet]. México: Secretaría de Salud, Secretaría de Prevención y Promoción de la Salud; 20/04/2021. Disponible en: https://www.gob.mx/salud/acciones-y-programas/covid19-informacion-relevante Tablero de Control, Mapas, Casos y Tasas https://covid19.sinave.gob.mx/

3. Martínez SJ, Torres RC, Orozco RE. Características, medidas de política pública y riesgos de la pandemia del Covid-19 [Internet]. México: Senado de la República; 20 de marzo de 2020. Disponible en: http:// bibliodigitalibd.senado.gob.mx/handle/123456789/4816
4. World Health Organization. WHO Coronavirus (COVID-19) Dashboard [Internet]. World Health Organization; 2020. Disponible en: https://covid19.who.int/

5. Organización Mundial de la Salud. Preguntas y respuestas sobre la enfermedad por coronavirus (COVID-19) [Internet]. Organización Mundial de la Salud; 2020. Disponible en: https://www.who.int/es/emergencies/ diseases/novel-coronavirus-2019/advice-for-public/q-a-coronaviruses

6. Riza Sahin A, Erdogan A, Mutlu Agaoglu P, Dineri Y, Cakirci AY, Egemel Senel M, et al. Novel coronavirus (COVID-19) outbreak: A review of the current literature. EJMO. 2020;4(1):1-7.

7. Guan W-J, Ni Z-Y, Hu Y, Liang W-H, Ou C-Q, He J-X, et al. Clinical characteristics of coronavirus disease 2019 in China. N Engl J Med. 2020;382:1708-20.

8. Siddiqi HK, Mehra MR. COVID-19 illness in native and immunosuppressed states: A clinical-therapeutic staging proposal. J Heart Lung Transplant. 2020;39(5):405-7.

9. Huang Ch, Wang Y, Li X, Ren L, Zhao J, Hu Y, et al. Clinical features of patients infected with 2019 novel coronavirus in Wuhan, China. Lancet. 2020;395:497-506.

10. Su S, Wong G, Shi W, Liu J, Lai ACK, Zhou J, et al. Epidemiology, genetic recombination, and pathogenesis of coronaviruses. Trends Microbiol. 2016;24(6):490-502.

11. Tang B, Bragazzi NL, Li Q, Tang S, Xiao Y, Wu J. An updated estimation of the risk of transmission of the novel coronavirus (2019-nCov). Infect Dis Model. 2020;5:248-55.

12. Hoffmann M, Kleine-Weber H, Schroeder S, Krüger N, Herrler T, Erichsen S, et al. SARS-CoV-2 cell entry depends on ACE2 and TMPRSS2 and is blocked by a clinically proven protease inhibitor. Cell. 2020;181(2):271-80.e8.

13. Yi Y, Lagniton P, Ye S, Li E, Xu RH. COVID-19: what has been learned and to be learned about the novel coronavirus disease. Int J Biol Sci. 2020;16(10):1753.

14. Lin L, Lu L, Cao W, Li T. Hypothesis for potential pathogenesis of SARSCoV-2 infection -a review of immune changes in patients with viral pneumonia. Emerg Microbes Infect. 2020;9(1):727-32.

15. Swiss Institute of Bioinformatics (SIB). ACE2 $\otimes$ Angiotensin-converting enzyme 2 [Internet]. Swiss Institute of Bioinformatics [consultado: 20 abril 2020]. Disponible en: https://www.nextprot.org/entry/NX_Q9BYF1/ expression

16. Phillips N, Park I, Robinson J, Jones H. The perfect storm: COVID-19 health disparities in US blacks. J Racial Ethn Health Disparities. 2020 Sep 23:1-8. doi: 10.1007/s40615-020-00871-y. Online ahead of print.

17. Iwasaki A. What reinfections mean for Covid-19. Lancet. 2020; 21(1):3-5.

18. Beacon TH, Su RC, Lakowski TM, Delcuve GP, Davie JR. SARS-CoV-2 multifaceted interaction with the human host. Part II: Innate immunity response, immunopathology, and epigenetics. IUBMB Life. 2020; 72(11):2331-54.

19. Azkur AK, Akdis M, Azkur D, Sokolowska M, van de Veen W, Brüggen $\mathrm{MC}$, et al. Immune response to SARS-CoV-2 and mechanisms of immunopathological changes in COVID-19. Allergy. 2020;75(7):1564-81.

20. Catanzaro M, Fagiani F, Racchi M, Corsini E, Govoni S, Lanni C. Immune response in COVID-19: addressing a pharmacological challenge by targeting pathways triggered by SARS-CoV-2. Signal Transduct Target Ther. 2020;5(1):84.

21. Liao M, Liu Y, Yuan J, Wen Y, Xu G, Zhao J, et al. Single-cell landscape of bronchoalveolar immune cells in patients with COVID-19. Nat Med. 2020;26(6):842-4.

22. Qin C, Zhou L, Hu Z, Zhang S, Yang S, Tao Y, et al. Dysregulation of immune response in patients with coronavirus 2019 (COVID-19) in Wuhan, China. Clin Infect Dis. 2020;71(15):762-8.

23. Zhang $\mathrm{H}$, Liu $Y$, Rao L, Cen $Y$, Cheng K. Effects of the combination of Herba Epimedii and Semen Plentaginis on the aortic ACE2/Angiotensin-(1-7)/Mas receptor axis and blood pressure in spontaneously hypertensive rats. Int J Clin Exp Med. 2019;12(4):3376-86.

24. Vabret N, Britton GJ, Gruber C, Hegde S, Kim J, Kuksin M, et al. Immunology of COVID-19: Current state of the science. Immunity. 2020;52(6):910-41.

25. Blanco-Melo D, Nilsson-Payant BE, Liu WC, Uhl S, Hoagland D, Møller $\mathrm{R}$, et al. Imbalanced host response to SARS-CoV-2 drives development of COVID-19. Cell. 2020;181(5):1036-45.e9.

26. Xie B, Zhang J, Li Y, Yuan S, Shang Y. COVID-19: Imbalanced immune responses and potential immunotherapies. Front Immunol. 2021;11:1-16.

27. Noris M, Benigni A, Remuzzi G. The case of complement activation in COVID-19 multiorgan impact. Kidney Int. 2020;98:314-22.

28. Risitano AM, Mastellos DC, Huber-Lang M, Yancopoulou D, Garlanda C, Ciceri F,et al. Complement as a target in Covid-19? Nature Reviews Immunology. 2020;20:343-4.

29. Polycarpou A, Howard M, Farrar CA. Rationale for targeting complement in COVID-19. EMBO Mol Med. 2020:12(8):e12642. 
30. Magro C, Mulvey JJ, Berlin D, Nuovo G, Salvatore S, Harp J, et al Complement associated microvascular injury and thrombosis in the pathogenesis of severe COVID-19 infection: a report of five cases. Transl Res. 2020;220:1-13.

31. Waggoner SN, Cornberg M, Selin LK, Welsh RM. Natural killer cells act as rheostats modulating antiviral T cells. Nature. 2011;481(7381):394-8.

32. Jain A, Pasare C. Innate control of adaptive immunity: Beyond the three-signal paradigm. J Immunol. 2017;198(10):3791-800.

33. Sette A, Crotty S. Adaptive immunity to SARS-CoV-2 and COVID-19. Cell. 2021;184(4):861-80.

34. Maucourant Ch, Filipovic I, Ponzetta A, Aleman S, Cornillet M, Hertwig L, et al. Naturall killer cell immunotypes related to COVID-19 disease severity. Sci Immunol. 2020;5(50):28-34.

35. Laing AG, Lorenc A, Del Molino Del Barrio I, Das A, Fish M, Monin L, et al. A consensus Covid-19 immune signature combines immuno-protection with discrete sepsis-like traits associated with poor prognosis [Internet]. medRxiv; 2020. Disponible en: https://www.medrxiv.org/conten$\mathrm{t} / 10.1101 / 2020.06 .08 .20125112 \mathrm{v} 1$

36. Mathew D, Giles JR, Baxter AE, Oldridge DA, Greenplate AR, Wu JE, et al. Deep immune profiling of COVID-19 patients reveals distinct immunotypes with therapeutic implications. Science. 2020;369(6508):eabc851.

37. Tan L, Wang Q, Zhang D, Ding J, Huang Q, Tang YQ, et al. Lymphopenia predicts disease severity of COVID-19: a descriptive and predictive study. Signal Transduct Sig Transduct Target Ther. 2020;5(1):33.

38. Chua RL, Lukassen S, Trump S, Hennig BP. Wendisch D, Pott F, et al. COVID-19 severity correlates with airway epithelium-immune cell interactions identified by single-cell analysis. Nat Biotech. 2020;38(8):970-9.

39. Diao B, Wang C, Tan Y, Chen X, Liu Y, Ning L, et al. Reduction and functional exhaustion of T cells in patients with coronavirus disease 2019 (COVID-19). Front Immunol. 2020;11:827.

40. Thevarajan I, Nguyen TH, Koutssakos M, Druce J, Caly L, van de Sandt $\mathrm{CE}$, et al. Breadth of concomitant immune responses prior to patient recovery: a case report of non-severe COVID-19. Nat Med. 2020;26:453-5.

41. Grifoni A, Weiskopf D, Ramirez SI, Mateus J, Dan JM, Moderbacher CR, et al. Targets of T cell responses to SARS-CoV-2 coronavirus in humans with COVID-19 disease and unexposed individuals. Cell. 2020;181:1489-501.e15.

42. Nelde A, Bilich T, Heitmann JS, Maringer Y, Salih HR, Roerden M, et al. SARS-CoV-2-derived peptides define heterologous and COVID-19-induced T cell recognition. Nat Immunol. 2021;22:74-85.

43. Peng Y, Mentzer AJ, Liu G, Yao X, Yin Z, Dong D, et al. Oxford Immunology Network Covid- 19 Response T cell Consortium; ISARIC4C Investigators. Broad and strong memory CD4+ and CD8+ T cells induced by SARS-CoV-2 in UK convalescent individuals following COVID-19. Nat Immunol. 2020;21:1336-45.

44. Khan D, Ahmed S. The immune system is a natural target for estrogen action: Opposing effects of estrogen in two prototypical autoimmune diseases. Front Immunol. 2016;6:635.

45. Barañao R. Hormonas sexuales y respuesta inmunitaria. AEGRE. 2009;16(1):30

46. Ghosh S, Klein RS. Sex drives dimorphic immune responses to viral infections. J Immunol. 2017;198(5):1782-90.
47. Grandi G, Facchinetti F, Bitzer J. The gendered impact of coronavirus disease (COVID-19): do estrogens play a role? Eur J Contracept Reprod Health Care. 2020;25(3):233-4.

48. Breithaupt-Faloppa AC, Correia CJ, Prado CM, Sessa Stilhano R, Portes Ureshino R, Pinho Moreira LF. 17b-estradiol, a potential ally to alleviate SARS-CoV-2 infection. Clinics. 2020;75:e198.

49. Channappanavar R, Fehr AR, Vijay R, Mack M, Zhao J, Meyerholz DK, et al. Dysregulated type I interferon and inflammatory monocyte-macrophage responses cause lethal pneumonia in SARS-CoV-infected mice. Cell Host Microbe. 2016;19:181-93.

50. Mompeón A, Lázaro-Franco M, Bueno-Betí C, Pérez-Cremades D, Vidal-Gómez X, Monsalve $\mathrm{E}$, et al. Estradiol, acting through $\mathrm{ER} \alpha$, induces endothelial non-classic renin-angiotensin system increasing angiotensin 1-7 production. Mol Cell Endocrinol. 2016;422:1-8.

51. Hulme KD, Gallo LA, Short KR. Influenza virus and glycemic variability in diabetes: A killer combination? Front Microbiol. 2017:8:861.

52. Chen N, Zhou M, Dong X, Qu J, Gong F, Han Y, et al. Epidemiological and clinical characteristics of 99 cases of 2019 novel coronavirus pneumonia in Wuhan, China: a descriptive study. Lancet. 2020;395:507-13.

53. Islam M, Hoque M, Shaminur Rahman M, Rubayet Ul Alam ASM, Akther M, Akter Puspo J, et al. Genome-wide analysis of SARS-CoV-2 virus strains circulating worldwide implicates heterogeneity. Sci Rep. 2020;10:14004.

54. Brassey J, Heneghan C, Mahtani KR, Aronson JK. Do weather conditions influence the transmission of the coronavirus (SARS-CoV-2)? [Internet]. Centre for Evidence-Based Medicine, Nuffield Department of Primary Care Health Sciences, University of Oxford; 23 de marzo de 2020. Disponible en: https://www.cebm.net/covid-19/do-weather-conditions-influence-the-transmission-of-the-coronavirus-sars-cov-2/

55. To KK, Hung IF, Chan KH, Yuan S, To WK, Tsang DN, et al. Serum antibody profile of a patient with COVID-19 reinfection. Clin Infect Dis. 2020 Sep 23:ciaa1368. doi: 10.1093/cid/ciaa1368. Online ahead of print.

56. To KK, Hung IF, Ip JD, Chu AW, Chan WM, Tam AR, et al. COVID-19 re-infection by a phylogenetically distinct SARS-coronavirus-2 strain confirmed by whole genome sequencing. Clin Infect Dis. 2020 Aug 25:ciaa1275. doi: 10.1093/cid/ciaa1275. Online ahead of print.

57. Tillet RI, Sevinsky JR, Hartley PD, Kerwin H, Crawford N, Gorzalski A, et al. Genomic evidence for reinfection with SARS-CoV-2: a case study. Lancet 2020;21(1):52-8.

58. Kellam P, Barclay W. The dynamics of humoral immune responses following SARS- CoV-2 infection and the potential for reinfection. J Gen Virol. 2020;101:791-7.

59. Pairo-Castineira E, Clohisey S, Klaric L, Bretherick AD, Rawlik K, Pasko D, Walker S, et al. Genetic mechanisms of critical illness in COVID-19. Nature. 2021;591(7848):92-8.

60. Zerberg H, Pääbo S. A genetic variant protective against severe COVID-19 is inherited from Neandertals [Internet]. bioRxiv; 9 de octubre de 2020. Disponible en: https://www.biorxiv.org/content/10.1101/2020. 10.05.327197v3

61. Sams AJ, Dumaine A, Nédélec Y, Yotova V, Alfieri C, Tanner JE, et al. Adaptively introgressed Neandertal haplotype at the OAS locus functionally impacts innate immune responses in humans. Genome Biol. 2016;17:246. 